\title{
Acció conjunta i desenvolupament d'habilitats sensoriomotores a la sala de psicomotricitat
}

\author{
M. Asunción Martínez Vera \\ INS Vidal i Barraquer; mmarti102@xtec.cat \\ Sandra Gilabert Medina \\ Universitat Rovira i Virgili; sandra.gilabert@urv.cat \\ Isabel Viscarro Tomàs \\ Universitat Rovira i Virgili
}

Resum: Aquest treball parteix de la teoria sociocultural de Vygotsky, en què la interacció és clau en el desenvolupament de l'infant. Pretenem analitzar de quina manera infants de tres a quatre anys construeixen el coneixement psicomotor de manera conjunta a partir de l'estudi de la interacció dins del joc sensoriomotor. L'anàlisi de les seqüències d'interacció mostren una gran diversitat d'interaccions entre els infants. D'altra banda, es posa de manifest que el paper de guia del psicomotricista deixa l'espai necessari perquè els infants creïn contextos d'acció propis.

Paraules clau: psicomotricitat, interacció, aprenentatge, joc sensoriomotor, paper del psicomotricista

\begin{abstract}
This work is based on Vygotsky's sociocultural theory which asserts that interaction is key to a child's development. We study of sensory interaction during sensory motor play to determine how children aged 3 to 4 years construct psychomotor knowledge. Analysis of the interaction sequences showed a variety of interactions among children. The study also found that the guidance provided by the psychomotrician gave children the space they needed to create their own contexts of action.
\end{abstract}

Keywords: psychomotricity, interaction, learning, sensory motor play, role of psychomotrician 


\section{Introducció}

El present treball vol contribuir a una millor comprensió del paper que l'accide les habilitats motrius ó conjunta dels infants juga en el desenvolupament de les habilitats motrius.

Entenem l'aprenentatge com el resultat de les interaccions socials en què els infants s'enfronten a problemes conjuntament amb adults o altres infants (Vygotsky, 1978; 1981). Des d'aquesta perspectiva, l'estimulació del desenvolupament requereix l'activitat compartida i es fa possible quan l'educador és capaç de generar espais d'interacció o zones de desenvolupament pròxim en què l'infant pugui desenvolupar noves competències.

Els estudis consultats amb aquest enfocament s'han centrat en l'anàlisi de la interacció a l'aula en alumnes d’educació primària i educació secundària (Coll, 1993; Coll i Onrubia, 1996; Sharan, 1980, Johnson i Johnson, 1995), deixant de banda els aprenentatges psicomotors que els infants d'educació infantil realitzen en contextos de joc lliure.

Altres estudis realitzats en contextos de pràctica psicomotriu relacional (Aucouturier, Lapierre, entre d'altres) han posat de manifest tant la dimensió simbòlica del joc psicomotor com el valor de l'activitat autònoma i la importància del grup com a impulsor d'aprenentatges. Aquestes investigacions, però, han deixat de banda aspectes que podrien ser claus per a la intervenció en l'àmbit psicomotriu i que abastarien tant la definició de les formes que l'activitat compartida adopta com la seva relació amb les habilitats que posen en joc i amb l'organització dels contextos que les afavoreix.

Per tal de donar resposta a les qüestions que ens plantegem, ens hem centrat en l'observació d'infants de segon cicle d'educació infantil capaços d'usar el llenguatge verbal per comunicar i representar la realitat. Un llenguatge que, més enllà de l'egocentrisme piagetià, els permetrà en primer lloc l'aparició de la parla interior d'origen social i en segon lloc l'accés a la pragmàtica i a la parla social (Vygotsky, 1981). Aquests darrers seran essencials per la interacció, però no únics, ja que volem destacar que les categories dissenyades per analitzar la interacció s'han creat pensant en la interacció entesa tant en els espais de comu- nicació verbal com en els espais de comunicació no verbal compartits pels infants objecte d'estudi (Martínez Vera, 2009).

\section{Objectius del treball}

Aquest treball pretén evidenciar les maneres en què els infants construeixen el coneixement psicomotor de manera conjunta. Per aconseguir aquest propòsit, s'ha observat el joc interactiu de caràcter sensoriomotor que es produeix durant la sessió de psicomotricitat i s'han concretat els objectius següents:

- Descriure les formes d'interacció que es produeixen durant la fase sensoriomotora de la sessió de psicomotricitat entre infants de tres a quatre anys.

- Relacionar els materials proposats per l'educadora amb els tipus de joc que faciliten.

- Identificar el paper de l'adult en aquestes interaccions.

\section{Mètode}

\section{Opció metodològica}

Aquest és un estudi fet a escala petita que pretén trobar el significat de les interaccions entre infants en tota la seva complexitat, la qual cosa ens situa en la metodologia qualitativa, concretament en la investigació-acció, ja que analitza una situació educativa amb l'objectiu de millorar-ne la qualitat (Stenhouse, 1987).

\section{Focus d'atenció}

Latenció se centra en el joc sensoriomotor que els infants realitzen de manera espontània durant la fase d'activitat motriu i joc (Viscarro et al., 2010). Es focalitza en els processos i en les seqüències abans que en els resultats i en les freqüències que apareixen al llarg de la sessió.

\section{Context d'observació}

El context d'observació és la sala de psicomotricitat. S'analitzen tres sessions de psicomotricitat en què participen infants de tres a quatre anys de l'Escola de Pràctiques de Tarragona juntament amb la mestra-psicomotricista. 
El plantejament de les sessions de psicomotricitat se situa en la línia dinàmica-relacional que té com a punt de partida l'educació vivenciada proposada per A. Lapierre i B. Aucouturier (1977).

Amb la sala preparada s'inicia la sessió rebent els infants; un cop s'han saludat, se'ls demana que es treguin les sabates. Visualitzen els diferents espais de joc creats amb materials grans: tous i durs, fixos i mòbils, organitzats per oferir a l'infant varietat en les possibilitats d'acció, perquè puguin crear, innovar i imaginar a través de l'experimentació, la manipulació i la construcció, i es recorden les normes de la sala que faciliten un ambient assegurador. Coincidim amb Cardona (2013:47) quan diu que "a la sala de psicomotricitat es dóna l'oportunitat als infants d'actuar a partir d'allò que volen i poden fer".

S'inicia la fase d'activitat motriu i joc amb una activitat impulsiva: tombar un mur de blocs d'escuma. A continuació es diversifiquen i de manera espontània van als diferents racons, espais i circuits preparats prèviament per la sessió, que en termes generals són:
- Circuit: compost per rampes, túnels, cilindres elevats, balancins, matalassos. Els infants han pogut viure el plaer de moure's, de fer equilibris i desequilibris, d'arrossegar-se, de realitzar diferents desplaçaments, de fer girs i tombarelles.

- Racó de l'espatllera i el gronxador: joc d'estimulació vestibular que fomenta la integració sensorial relacionada amb el moviment, la gravetat i l'equilibri. Les accions que han fet son enfilar-se, baixar, pujar, saltar, girar, balancejar-se.

- Racó del trampolí: els ha permès viure el plaer del salt sobre una superfície desequilibrant i ajustar el to, la postura i l'equilibri tant sobre el trampolí com en la caiguda als matalassos.

- Joc d'experimentació corporal amb les peces d'escuma: amb el blocs d'escuma un cop tombat el mur, els infants han creat noves formes, nous espais, noves realitats.

- Joc de construcció amb fustes.

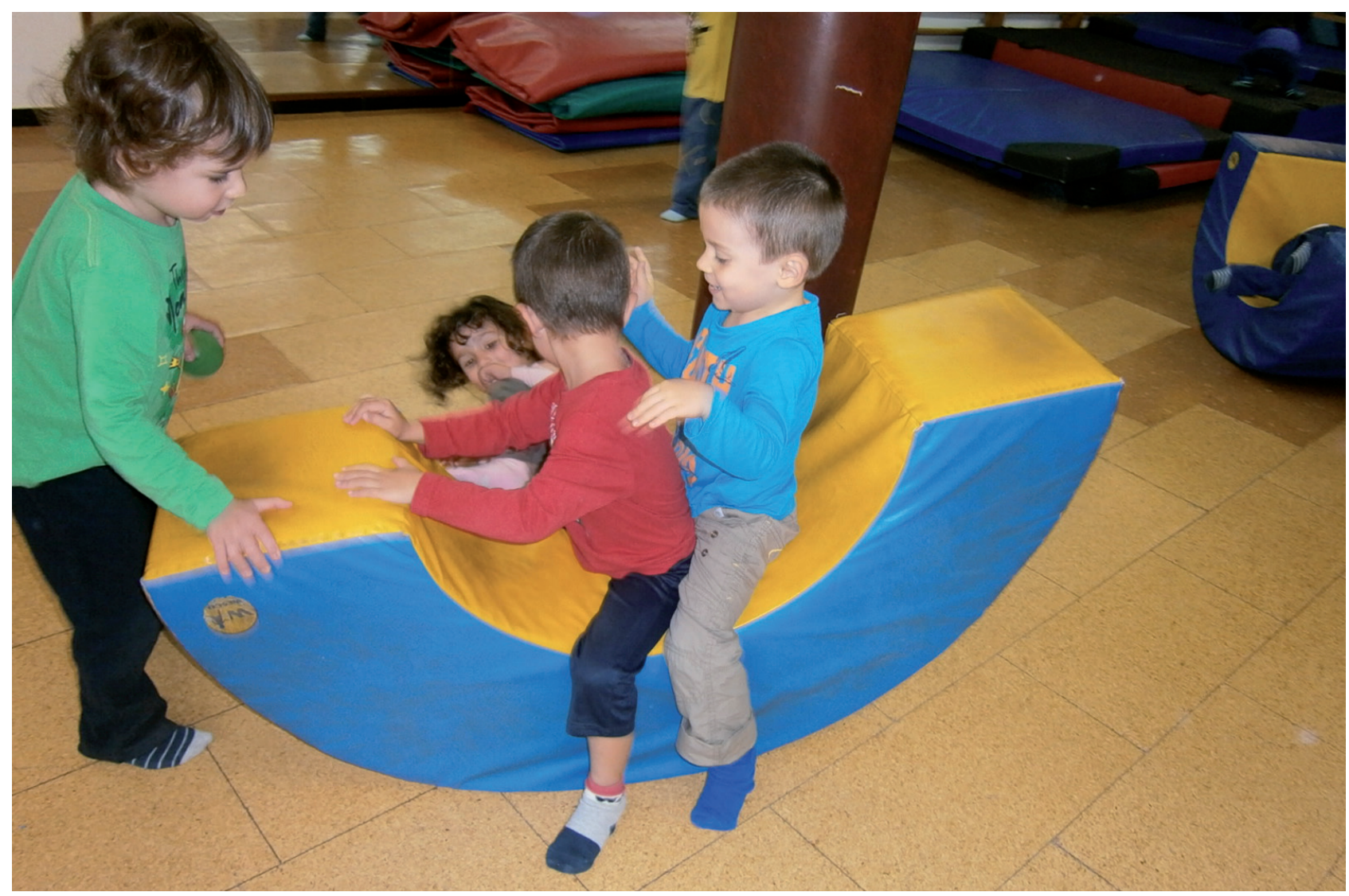


Un cop s'acaba el temps del treball corporal espontani, es proposa una activitat de tornada a la calma.

Finalment es realitza una conversa perquè l'infant pugui pensar allò que ha viscut durant la fase d'activitat motriu i joc, i s’acaba la sessió amb l'acomiadament dels infants.

\section{Recopilació de dades}

Les sessions enregistrades segueixen la mateixa estructura, tot i que es modifica la distribució i col-locació dels materials i se n'incorporen de nous. La recopilació de dades s'ha fet en el context habitual de pràctica educativa sense introduir cap variació, excepte la presència de la persona que les enregistra. Aquesta s'ha limitat a fer l'enregistrament en vídeo sense tenir cap paper actiu en el desenvolupament de la sessió. Partint d'una visió panoràmica, la càmera ha enfocat situacions de joc interactiu que han anat sorgint de manera espontània, tot corrent el risc de no enregistrar altres interaccions que es podien produir de manera simultània.

\section{Procés d’anàlisi}

El procés d'anàlisi s'ha fet en dos moments. En el primer, s'ha intentat reconèixer les unitats d'anàlisi o seqüències interactives, identificant els participants, les metes de l'activitat i els patrons de comportament. En el segon nivell s'aplica un sistema de categories que té en compte l'acció conjunta dels infants en els jocs estudiats.

\section{Categories d'anàlisi}

Les categories s'han definit prèviament de manera genèrica a partir del marc teòric, de l'experiència prèvia de les investigadores i dels resultats d'un treball realitzat amb anterioritat per una d’elles (Martínez Vera, 2009).

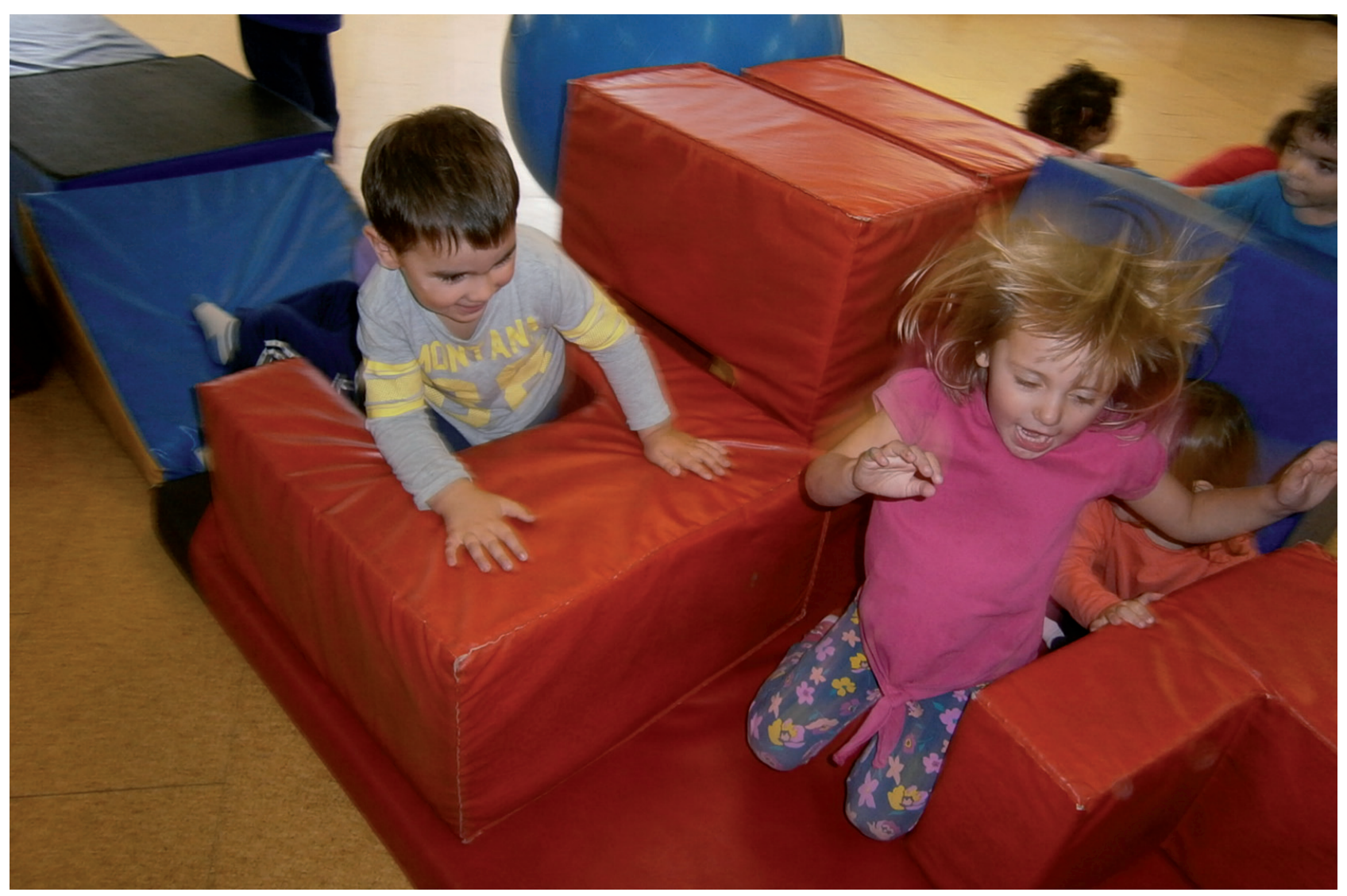


Taula 1. Quadre de categorització

\begin{tabular}{|c|c|c|}
\hline \multirow{6}{*}{ 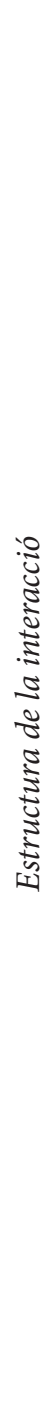 } & $\begin{array}{l}\text { Rols dels } \\
\text { participants }\end{array}$ & $\begin{array}{l}\text { Indiferenciats } \\
\text { Diferenciats } \\
\text { Complementari } \\
\text { Actiu } \\
\text { Passiu } \\
\text { Idèntics } \\
\text { Oposats } \\
\text { Absència de rols }\end{array}$ \\
\hline & $\begin{array}{l}\text { Reciprocitat } \\
\text { de les accions }\end{array}$ & $\begin{array}{l}\text { Alta } \\
\text { Mitja } \\
\text { Baixa } \\
\text { Cessió de torns } \\
\text { Cessió d'espai } \\
\text { Cessió de temps }\end{array}$ \\
\hline & $\begin{array}{l}\text { Metes } \\
\text { perseguides }\end{array}$ & $\begin{array}{l}\text { Compartides } \\
\text { No compartides } \\
\text { Oposades } \\
\text { Complementàries }\end{array}$ \\
\hline & $\begin{array}{l}\text { Instruments } \\
\text { d'interacció }\end{array}$ & $\begin{array}{l}\text { Mirada } \\
\text { Verbalitzacions } \\
\text { Canvi de to } \\
\text { Expressió facial } \\
\text { Gest corporal } \\
\text { Canvi postural } \\
\text { Desplaçaments } \\
\text { Manipulacions } \\
\text { Imitació }\end{array}$ \\
\hline & $\begin{array}{l}\text { Gestió de la } \\
\text { interacció }\end{array}$ & $\begin{array}{l}\text { Autònoma } \\
\text { Compartida } \\
\text { Asimètrica }\end{array}$ \\
\hline & Entesa & $\begin{array}{l}\text { Acord } \\
\text { Acceptació } \\
\text { Desacord }\end{array}$ \\
\hline
\end{tabular}

\section{Confiabilitat de les observacions}

La triangulació d'investigadores i de dades recollides en diferents moments garanteixen la validesa de l'instrument i la confiabilitat de les observacions realitzades.

\section{Generalització dels resultats}

Els resultats que es presenten no permeten ser generalitzats més enllà d'altres situacions que comparteixin amb aquestes l'àmbit, el context educatiu i les competències dels infants.

\begin{tabular}{|c|c|c|c|}
\hline \multirow{3}{*}{$\frac{\frac{\pi}{3}}{\frac{\pi}{4}}$} & \multirow[t]{2}{*}{$\begin{array}{l}\text { Actuació } \\
\text { de l'adult }\end{array}$} & Intervé & $\begin{array}{l}\text { Dirigeix l'atenció } \\
\text { Demana prestar ajuda } \\
\text { Comenta l'acció d'un altre } \\
\text { Aporta materials nous } \\
\text { Proposa compartir materials } \\
\text { Respon la demanda }\end{array}$ \\
\hline & & No intervé & $\begin{array}{l}\text { Observador } \\
\text { Amb altres adults } \\
\text { Amb altres infants }\end{array}$ \\
\hline & $\begin{array}{l}\text { Situació } \\
\text { espacial } \\
\text { de l'adult }\end{array}$ & \multicolumn{2}{|c|}{$\begin{array}{l}\text { Proper } \\
\text { Llunyà } \\
\text { Compartint l'espai }\end{array}$} \\
\hline \multirow{9}{*}{ 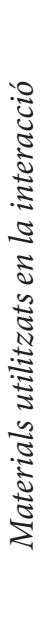 } & \multirow{3}{*}{ Tou } & \multicolumn{2}{|c|}{ Coixins, kits i blocs d'escuma } \\
\hline & & \multicolumn{2}{|c|}{ Pilotes gegants } \\
\hline & & \multicolumn{2}{|c|}{ Matalassos de diferents gruixos } \\
\hline & \multirow{2}{*}{ Dur } & \multicolumn{2}{|c|}{$\begin{array}{l}\text { Estructures fixes: espatlleres, escala } \\
\text { horitzontal, cordes suspeses del sostre }\end{array}$} \\
\hline & & \multicolumn{2}{|c|}{$\begin{array}{l}\text { Bancs suecs, barres d'equilibri, rampes, tacs } \\
\text { de fusta, llit elàstic. }\end{array}$} \\
\hline & \multirow{3}{*}{ Manipulable } & \multicolumn{2}{|c|}{ Pilotes de diferents diàmetres i textures } \\
\hline & & \multicolumn{2}{|c|}{ Cordes, bitlles, cèrcols, cons } \\
\hline & & \multicolumn{2}{|c|}{$\begin{array}{l}\text { Trossos de roba, mocadors, cintes i cintes } \\
\text { elàstiques }\end{array}$} \\
\hline & Reutilitzat & \multicolumn{2}{|c|}{$\begin{array}{l}\text { Capses de cartró, tubs de cartró, paper de } \\
\text { diari, envasos diversos }\end{array}$} \\
\hline
\end{tabular}

\section{Resultats}

L'anàlisi de les seqüències interactives enregistrades ha posat de manifest la diversitat $i$ varietat d'interaccions entre infants que es dóna en la sessió de psicomotricitat durant la fase d'activitat motriu i joc.

\subsection{Identificació i organització de les seqüències interactives}

El nombre de participants en cadascuna de les interaccions ha oscil.lat entre 2 i 7 infants. No hem pogut establir una relació clara entre durada de la interacció i nombre de participants, cosa que es va observar en infants més petits de 2 anys (Martínez Vera, 2009). 13 de les 18 seqüències analitzades tenen més de 4 participants. 
Gràfic 1. Nombre de participants

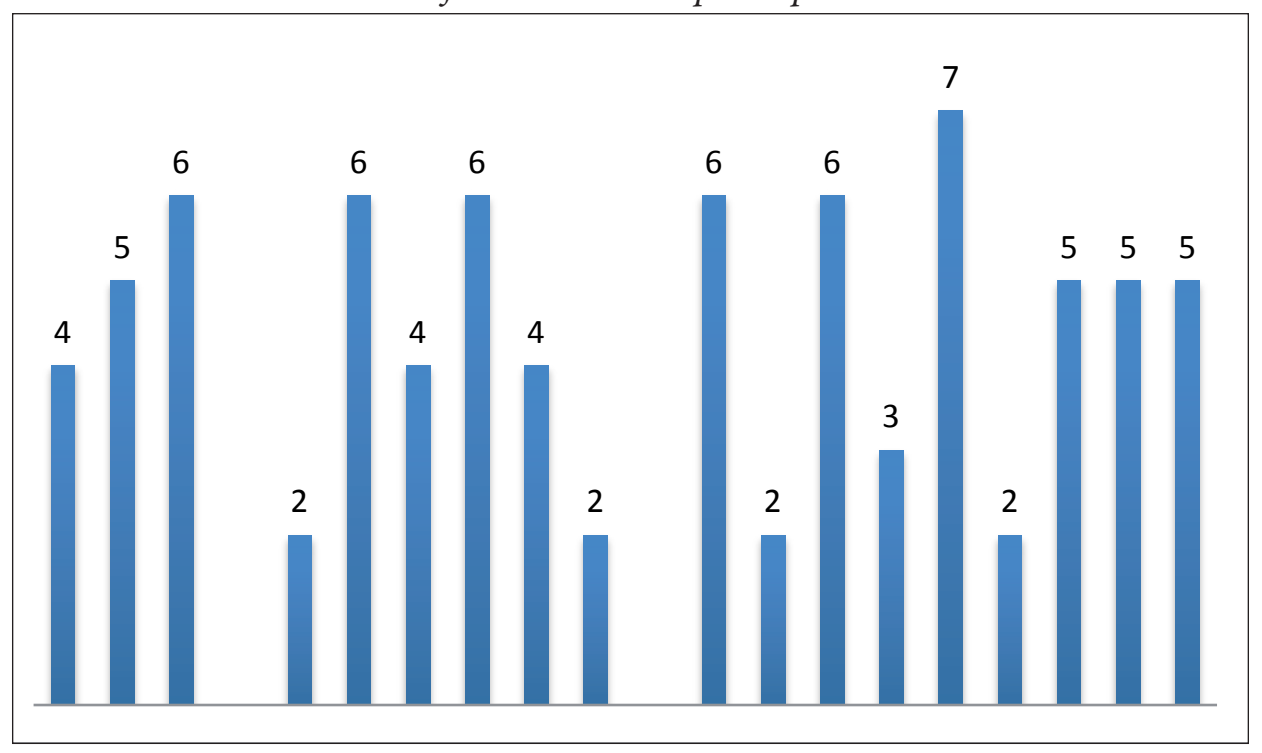

La taula 2 recull les interaccions que es produeixen a l'espai on se situa la càmera.

Els temps parcials de les interaccions observades i mostrades al gràfic 2 fluctuen de 0 ' 38 " a 9' 43". Només tres sobrepassen els 4 minuts.

\subsection{Paper de l'adult}

De les 20 interaccions observades, només en quatre ocasions la mestra psicomotricista ha fet una intervenció directa i molt breu relacionada amb el recordatori de normes i amb la seguretat.

Taula 2. Recull de les interaccions

\begin{tabular}{|l|l|c|c|c|}
\hline \multicolumn{1}{|c|}{ Ordre } & \multicolumn{1}{|c|}{ Seqüència interactiva } & $\begin{array}{c}\text { Durada } \\
\text { interacció }\end{array}$ & $\begin{array}{c}\text { Nombre } \\
\text { participants }\end{array}$ & $\begin{array}{c}\text { Actuació de } \\
\text { l'educadora }\end{array}$ \\
\hline Fragment 1 & Joc del tobogan & $01: 31$ & 4 & No intervé \\
\hline Fragment 2 & Joc d'arrossegaments & $01: 42$ & 5 & No intervé \\
\hline Fragment 3 & Joc amb blocs d'escuma & $01: 19$ & 6 & No intervé \\
\hline Fragment 4 & Joc del gronxador & $01: 47$ & & No intervé \\
\hline Fragment 5 & Joc del llit elàstic & $02: 12$ & 2 & No intervé \\
\hline Fragment 6 & Joc circuit & $02: 32$ & 6 & No intervé \\
\hline Fragment 7 & Joc túnel & $01: 47$ & 4 & No intervé \\
\hline Fragment 8 & Joc d'experimentació corporal & $03: 14$ & 6 & No intervé \\
\hline Fragment 9 & Entro, surto i m'equilibro (la roda) & $01: 39$ & 4 & Intervé \\
\hline Fragment 10 & Desequilibris amb el rul·lo & $00: 56$ & 2 & No intervé \\
\hline Fragment 11 & Joc de cordes a l'espatllera & $01: 47$ & & No intervé \\
\hline Fragment 12 & Estirem la roba & $09: 43$ & 6 & No intervé \\
\hline Fragment 13 & El balancí & $00: 52$ & 2 & No intervé \\
\hline Fragment 14 & Piscina bosses paper & 00.38 & 6 & No intervé \\
\hline Fragment 15 & El gronxador & $01: 14$ & 3 & No intervé \\
\hline Fragment 16 & Les peces, conflicte & $02: 48$ & 7 & Intervé \\
\hline Fragment 17 & Juguem amb les capses & $06: 35$ & 2 & No intervé \\
\hline Fragment 18 & Experimentem amb blocs d'escuma & $03: 51$ & 5 & Intervé \\
\hline Fragment 19 & Joc d'equilibris i desequilibris & $01: 51$ & 5 & Intervé \\
\hline Fragment 20 & Esquivem les gomes & $02: 31$ & 5 & No intervé \\
\hline
\end{tabular}


Gràfic 2. Durada de les interaccions observades

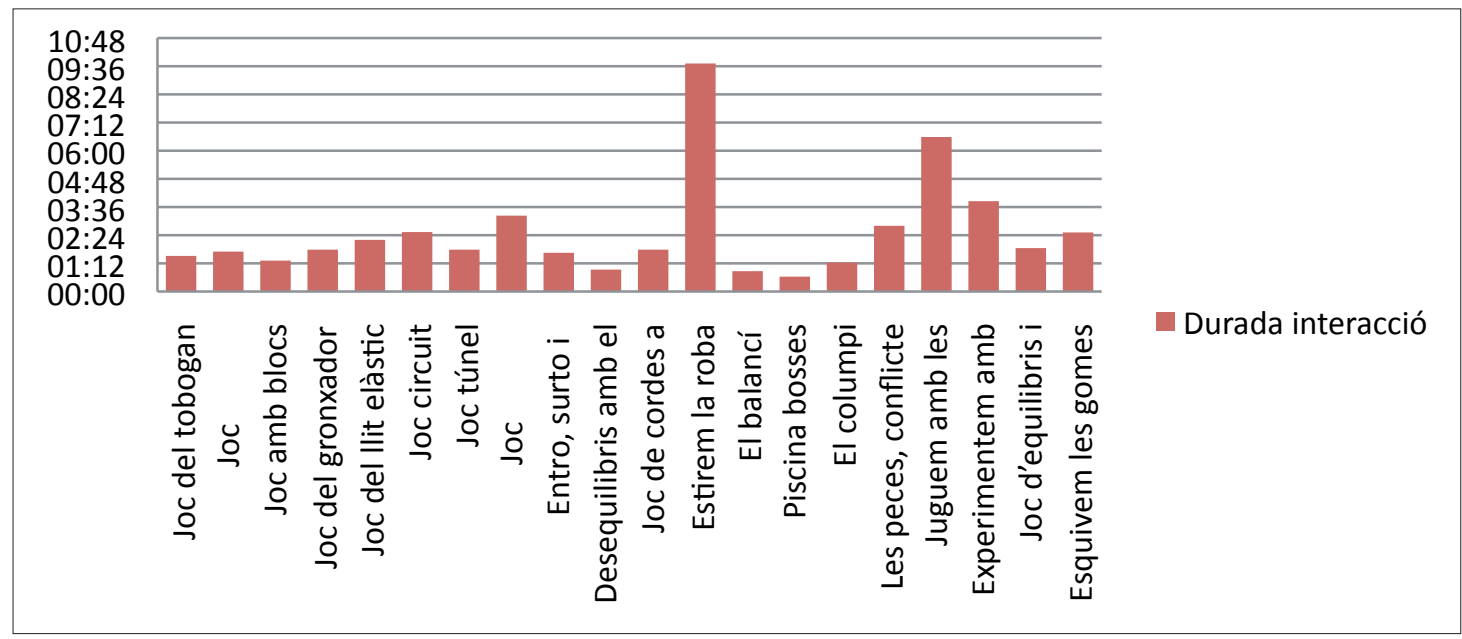

\subsection{Identificació dels formats d'interacció}

Cada una de les seqüències que han estat identificades s'han classificat en funció dels paràmetres següents:

La categorització de les dades ha posat de manifest l'aparició de quatre grans formats interactius: l'activitat conjunta, l'activitat en companyia, l'activitat competitiva i la de conflicte (Martínez Vera et alii, 2013). Lespecificació i caracterització de cada un d'aquets formats i subformats queda recollida a la taula 3 .

Els espais que faciliten interaccions més complexes en estructura (rols, mutualitat, metes compartides, gestió conjunta...) són aquells on els materials estan presentats de manera menys estructurada. Quan els materials estan organitzats en estructures menys transformables, els intercanvis observats tenen una estructura més simple.

Taula 3. Formats interactius

\begin{tabular}{|c|c|c|c|c|c|c|}
\hline \multirow[b]{2}{*}{$\begin{array}{c}\text { Formats } \\
\text { d'interacció }\end{array}$} & \multicolumn{2}{|c|}{ Activitat conjunta } & \multicolumn{2}{|c|}{ Activitat en companyia } & \multirow[b]{2}{*}{$\begin{array}{c}\text { Activitat } \\
\text { competitiva }\end{array}$} & \multirow[b]{2}{*}{$\begin{array}{l}\text { Activitat de } \\
\text { conflicte }\end{array}$} \\
\hline & Col.laborativa & D’ajuda & $\begin{array}{l}\text { Activitat } \\
\text { Imitació/ } \\
\text { observació }\end{array}$ & Activitat autònoma & & \\
\hline Rols & $\begin{array}{l}\text { Possibilitat que } \\
\text { apareguin rols } \\
\text { diferenciats }\end{array}$ & $\begin{array}{l}\text { Rols } \\
\text { diferenciats }\end{array}$ & Rols diferenciats & Indefinició de rols & Rols oposats & Rols oposats \\
\hline Reciprocitat & $\begin{array}{l}\text { Alta per tots els } \\
\text { participants }\end{array}$ & $\begin{array}{l}\text { Alta per tots els } \\
\text { participants }\end{array}$ & Baixa & $\begin{array}{l}\text { Baixa, relativa } \\
\text { a cessió de torn } \\
\text { principalment }\end{array}$ & Alta & Alta \\
\hline Metes & $\begin{array}{l}\text { Compartides. Les } \\
\text { metes només poden } \\
\text { ser assolides per } \\
\text { tots els participants } \\
\text { o per ningú }\end{array}$ & $\begin{array}{l}\text { Subsidiàries } \\
\text { una de l'altra }\end{array}$ & $\begin{array}{l}\text { Pròpies. Poden } \\
\text { ser assolides } \\
\text { sense lèxit dels } \\
\text { altres }\end{array}$ & $\begin{array}{l}\text { Pròpies encara que } \\
\text { coincidents amb els } \\
\text { dels altres. Poden } \\
\text { ser assolides sense } \\
\text { l'èxit dels altres. }\end{array}$ & Oposades & Oposades \\
\hline $\begin{array}{l}\text { Gestió de } \\
\text { l'activitat }\end{array}$ & $\begin{array}{l}\text { Compartida o } \\
\text { dirigida per un dels } \\
\text { participants }\end{array}$ & $\begin{array}{l}\text { Dirigida per un } \\
\text { dels participants }\end{array}$ & $\begin{array}{l}\text { Autònoma o } \\
\text { dirigida per un } \\
\text { dels participants }\end{array}$ & Autonomia & $\begin{array}{l}\text { Compartida } \\
\text { simètricament o } \\
\text { dirigida per un } \\
\text { dels participants }\end{array}$ & $\begin{array}{l}\text { Compartida } \\
\text { simètricament }\end{array}$ \\
\hline Entesa & Acord & Acord & Acord & Acord & $\begin{array}{l}\text { Acord o } \\
\text { acceptació }\end{array}$ & Desacord \\
\hline
\end{tabular}




\section{Conclusions}

Els resultats obtinguts posen de manifest el valor de la vida en grup (Aucouturier, 1985) i les competències que els infants de tres a quatre anys tenen per participar conjuntament amb altres.

Des de la psicologia sociocultural es considera que estar i actuar amb altres crea espais òptims d'aprenentatge (Vigotsky, 1978). Els resultats mostren com a la sessió de psicomotricitat, de manera espontània, els infants realitzen interaccions de gran complexitat amb les quals construeixen espais d'aprenentatge conjunt on posen en joc les seves habilitats motrius, intel-lectuals $i$ emocionals. En aquest sentit, volem destacar el paper que la participació del psicomotricista hi juga. La seva presència neutra deixa l'espai necessari perquè els infants creïn contextos d'acció propis

D'altra banda, les relacions que s'han establert entre l'organització dels espais i la complexitat de la interacció apunten a la necessitat de reflexionar sobre el grau d'estructuració dels materials de la sala que es proposen en les sessions. Les interaccions més complexes i cooperatives s'han donat en els racons que permetien els infants transformar l'espai de joc i posar a prova les seves capacitats d'imaginació, de creació i d'emoció, creant contextos més adequats a les seves necessitats i desitjos.

\section{Bibliografia}

Aucouturier, B.; Darrault, I.; Empinet, J.L. (1985) La práctica psicomotriz. Reeducación y terapia. Madrid: Científico-Medica.

Cardona, Y. (2013). "Psicomotricitat i intelligències múltiples. Compartint un espai" [En línia]. Comunicació Educativa, 26, 46-55. [Data de consulta: 20-05-2015].

$<$ http://revistes.publicacionsurv.cat/index.php/ comeduc/article/view/430/407>.
Coll, C. [et alii] (1993). El constructivismo en el aula. Barcelona: Grao Col. Biblioteca de aula.

Coll, C. i Onrubia, J. (1996). "La construcción de significados compartidos en el aula: actividad conjunta y dispositivos semióticos en el control y seguimiento mutuo entre profesor y alumnos". A Coll, C. y Edwards, D. Enseñanza, aprendizaje y discurso en el aula. Madrid: Fundación Infancia y Aprendizaje.

Johnson, D. W., \& Johnson, R. T. (1995). Teaching students to be peacemakers (3rd ed.). Edina, MN: Interaction Book Company.

Lapierre, A. i Aucouturier, B. (1977) Educación vivenciada (3 volums). Científico-Médica: Barcelona:

Martínez Vera, M.A. (2009). "Aprendre junts a la llar d'infants". [En línia] Xtec [14 de gener de 2013]. <http://www.xtec.cat/sgfp/llicencies/200809/memories/1908m.pdf $>$.

Martínez Vera, M.A.; Viscarro, I. ; Gilabert S. (2013) "Lanàlisi de la interacció en infants de segon cicle d’educació infantil a través del joc sensoriomotor". CD Actes 5è Congrés Europeu de Psicomotricitat. Barcelona.

Sharan, S. (1980) "Cooperative learning in small groups: Recent methods and effects on achievement, attitudes, and ethnic relations". Review of Educational Research, 50, 245-271.

Stenhouse, L. (1987). La investigación como base de la enseñanza. Morata: Madrid.

Viscarro, I. (coord.) [et alii] (2010). Psicomotricitat: de la Vivència a la Representació. ICE URV: Tarragona.

Vygotsky, L. S. (1978). El desarrollo de los procesos psicológicos superiores. Crítica: Madrid.

Vygotsky, L. S. (1981). "The genesis of higher mental functions". In W. WERTSCH (Ed.), The concept of activity in Soviet psychology, 144188. Sharpe: Armonk, NY. 